\title{
Does the consensus about the value of supervision in social work stifle research and innovation?
}

This special issue of the Aotearoa New Zealand Social Work journal focuses on the topic of supervision in social work. We wanted to set a broad scope by highlighting the importance of supervision for all: supporting and developing practice from education to leadership. Because, from looking at much of the published work to date, one could be forgiven for thinking that supervision in social work is something mainly for students and newly qualified practitioners. Nothing could be further from the truth. We believe, as do many others, that supervision is critical for students, practitioners and managers at all levels and stages of their career. When social workers do not have suitable space and time in which to stop, think, and reflect, their emotional and social wellbeing suffers, and they provide a poorer service for the individuals, families and communities they work with. It is pleasing to see that, in recent years, many organisations in the United Kingdom (UK) have been able to focus on, and by all accounts, improve the supervision they provide for students and early-career practitioners. The challenge to improve support for students and newly qualified social workers in Aotearoa New Zealand remains (Ballantyne et al., 2019; Hay, Maidment, Ballantyne, Beddoe, \& Walker, 2019). We should, with equal vigour, be doing the same for more experienced workers, supervisors, managers and leaders. Given the consensus that exists within the profession about the importance of supervision, there is no reason not to.

Yet this consensus is itself worth thinking about. Where does it come from and why? And if we all agree about the importance of supervision, why is that it has only become the focus relatively recently of serious social work research? (Sewell, 2018). It is now nearly a decade since Carpenter, Webb, and Bostock (2013) concluded that "the evidence base for the effectiveness of supervision...is weak" (p. 1843). And it is doubtful whether a repeat of this review now would come to a very different conclusion, despite the fine efforts of an increasing number of scholars. A recent Delphi study by Beddoe, KarvinenNiinikoski, Ruch, and Tsui (2016) found that, amongst a group of international experts, the need to develop an empirical evidence base for supervision, particularly in relation to people who use services, was (still) the clearest priority. Wherever our consensus about the importance of supervision comes from, it is not the result of an abundance of evidence.

The full explanation for the existence of this consensus is undoubtedly complex and recursive. Here we suggest just three possible reasons. First, many social workers have had positive experiences of supervision and of the difference it has made for their practice and their personal and professional well-being. By which we do not mean that all social workers consistently receive good supervision all of the time-unfortunately, we know that this is not the case (e.g., Turner-Daly \& Gordon, 2017). Yet of those who report poor experiences, a significant proportion are likely, at one time or another, to have experienced something much better, even if only when they were a student. As a result, there are many within the profession who can personally attest to the value of good supervision.

Second, it is a given that social work is an emotionally demanding profession and that students, workers and managers alike need support. Social workers are (for want of a
AOTEAROA

NEW ZEALAND SOCIAL WORK 31(3), 1-6. 
better word) exposed through their work to situations of trauma, harm, loss, grief, deprivation, oppression and discrimination. We do not mean to give the impression that social work can only ever be a grim profession. There are many examples which show quite the opposite (Hardy, 2015). It would also be wrong to suggest that the challenges faced by paid professionals are comparable to those experienced by many people who use services. Nonetheless, it is impossible to deny that, in order to do their job well, social workers need effective emotional and social support. Given the long history of supervision within social work, it should not be surprising that supervision is considered one of the best supportive mechanisms available.

Finally, our consensus view of supervision may be aided by a certain lack of clarity about what exactly we mean. There are few very precise definitions of it. The word supervision can be used to describe a relationship, a formal meeting and a process. Many academic papers on supervision do not define what kind of supervision they are discussing or evaluating, or which aspects of it. Supervision is something of a blank slate, onto which different commentators can project their own ideas of what it means. This flexibility is useful for promoting its importance and establishing a consensus. Public inspection bodies (such as Ofsted in England) can say that supervision is important because it ensures close management oversight of practice. The British Association of Social Workers and the Aotearoa New Zealand Association of Social Workers can say that supervision is important because it helps ensure the professional development of their members. Managers can say that supervision is important because it enables them to gather information from workers (Manthorpe, Moriarty, Hussein, Stevens, \& Sharpe, 2015). Employers can say that supervision is important because it helps improve staff job satisfaction and retention (Mor Barak, Travis, Pyun, \& Xie, 2009). And so on. Thus, when we ask whether supervision is important, it is rare to find anyone who disagrees-but what they mean by supervision may not be immediately obvious.

There are, of course problems, with each of these three reasons. As we have already alluded to, when language is used with a lack of precision, it makes it very much harder to know what we really mean. When we say that supervision is critical for emotional well-being, what do we mean by supervision and what do we mean by emotional well-being? For that matter, what do we mean by critical? Without being more precise about the different behaviours, relationships and processes contained within supervision, it is unlikely we will progress much beyond where we currently stand in relation to the evidence-base. O'Donoghue, Wong Yuh Ju, and Tsui's (2018) work on an evidence-informed supervision model is an excellent example of the kind of scholarship we could do with much more of. In relation to the argument that social workers need emotional support, we are not about to disagree. But we can ask whether supervision is necessarily the best way to provide this kind of support. Many people in different professions face similar challenges-without the kind of supervision that is so commonplace in social work. Might we find better outcomes from other kinds of intervention? And how do people in other professions manage without supervision? In healthcare services in the UK, for example, there are many thousands of people who benefit every month from attending Schwartz Rounds (Maben et al., 2018). Meeting the emotional needs of dozens of people at the same time may well prove to be a lot more cost-effective than trying to do so via a series of one-to-one meetings between supervisors and individual workers (assuming that is what we mean by supervision). As for the suggestion that personal experience is an important reason for the consensus, this may well be the case. But personal experiences cannot help us answer the kind of cost-effectiveness questions we have just mentioned, and neither can we use such evidence to address 
the counter-factual question-what would have been different without supervision (particularly if we want to know what would have happened if something else was available instead)? Providing high-quality supervision takes a great deal of time, skill and effort. What benefits do we get for all of this input for staff and for people who use services, and what other potential benefits might we be missing out on as a result?

The consensus that exists about the importance of supervision can therefore be seen as a two-sided coin. On the one hand, having a consensus is good. It shows the extent to which we can agree with one another (and there remains plenty in social work about which reasonable people may disagree). A consensus enables us to stop debating (to some extent) and start doing. Yet having a consensus also creates some challenges. It results in some important questions being left un-asked-or even unrecognised. It can delay, perhaps indefinitely, the development of an evidencebase. After all, why dedicate funding resources, time and effort to produce the evidence that supervision works when everyone already agrees that it does? A consensus may also lead us to overlook examples of how supervision can actually be harmful (Beddoe, 2017; Ellis, Creaner, Hutman, \& Timulak, 2015). In fact, there may be nothing more useful for making progress in theory and evidence-generation than a bit of healthy (and respectful) disagreement, or at least a comparison of different points of view. Which brings us neatly onto the articles within this special edition....

This issue contains eight full-length articles which will contribute to the ongoing scholarship of supervision. The contents include a mix of qualitative, quantitative and theoretical approaches. First up, David Wilkins considers the important question, "does social work supervision work?" Wilkins takes methodological inspiration from realist approaches to evaluation to set out an initial working theory of social work supervision for child and family services, developed from an analysis of six reviews of the supervision literature. Wilkins concludes by arguing that this working theory offers the basis for future evaluative studies of supervision. It is our hope that further scholarship in this important topic will produce both rich findings and an evolving theory of supervision.

In 'Ngā Aroro and social work supervision', Eliza Wallace, Ngāpuhi, Te Rarawa, explores the interconnectedness of ngā aroro (key concepts) from Te Ao Māori that influence critical reflection in supervision and enhance the cultural effectiveness of supervision. Wallace presents not only rich findings from her qualitative study but also describes the embedding of research principles and ethics grounded in kaupapa Māori (Māori approaches). This methodology provides "a supportive shelter for consciousness-raising, critical dialogue, reflection on supervision practice and for oral cultural narrative to be honoured". The article challenges us to take a fresh view of supervision theory and practice, considering the strengths of supervision provided by non-registered social work supervisors and the cultural significance of supervision being developed and evaluated with indigenous aspirations at the centre.

Matt Rankine's article, 'The internal / external debate: The tensions within social work supervision', reports findings from qualitative discussions with key informants and supervisory dyads in community-based child welfare services regarding reflective practices in supervision. Internal and external supervision arrangements were a common topic of discussion in the study. Rankine's analysis identified important themes including the contribution of external supervision to "building capacity, resilience and confidential reflective space"; the focus of internal supervision on managerial and organisational agendas; tensions associated with external supervision regarding funding; and organisational and professional accountability.

In 'Supervising the supervisors: What support do first-line supervisors need to be more 
effective in their supervisory role?', Frances Patterson's theoretical article explores the transitions of those stepping into the supervisor role. Drawing on the experience of teaching managers on post-qualifying courses in professional supervision in Scotland, Patterson argues that the reflective supervisory needs of supervisors deserve greater priority. Supervisors in many countries have minimal training for the role (often short internal courses only), and few opportunities for ongoing professional development. Patterson's review of the containment function of supervision "makes evident a flawed logic if support for the emotional impact of the work is offered only to direct practitioners" given managers often hold the responsibility for their team's work.

In the first of two articles in this issue, Kieran O'Donoghue reports on a national survey on the supervision of registered social workers in Aotearoa New Zealand. A postal survey of 278 registered social workers was conducted to gain information about their supervision, and to compare with the Social Workers Registration Board's (SWRB) policy and guidelines. This is a very helpful report as it establishes much detail about various aspects of supervision, including forms, overall emphasis, logistics, types of contact, climate, methods and processes, experiences of their supervisor's approaches and models, session processes and content and their overall satisfaction and evaluation. Such information will usefully inform future supervision research in Aotearoa New Zealand. O'Donoghue reports from this survey that most registered social workers' supervision is in accordance with SWRB policy but that further work is needed to address the cultural responsiveness of supervision in relation to supervisees and service users. Suggestions are made concerning further research about the influence of gender, culture, sexual orientation, experience, qualifications, and registration status on supervision relationships.

In 'Courageous conversations in supervision,' Allyson Davys notes that challenging conversations, commonly associated with some form of emotion, are features of many social workers' daily routine and frequently appear on the supervision agenda. This article focuses on the supervisor's role in courageous conversations and identifies some of the obstacles to addressing difficult situations. Davys emphasises the importance of supervision contracts in the establishment of clear expectations and the development of an effective supervision relationship, whilst recognising the power inherent in the supervision process. Davys identifies three kinds of interventions: relational, reflective, and confrontational. The framework presented highlights the need for clarity about the motivation for, and purpose of, a courageous conversation and for clear identification of the desired goal or outcome.

'Professional supervision and professional autonomy' is the title of the contribution by Synnove Karvinen-Niinikoski, Liz Beddoe, Gillian Ruch, and Ming-sum Tsui. This article has previously appeared in chapter form in Blom, Evertsson, and Perlinski (2017) and is based on the authors' Delphi study (Beddoe et al., 2016). In this contribution the authors theorise the tension between supervision as being, on the one hand, a surveillant tool of management and on the other, a practice of critical reflection. They argue that such tensions pose a threat to professional social work autonomy and agency. An alternative, theoretically grounded approach is suggested, building on traditions of critically reflective supervision. Considering professional supervision within the frame of human agency will help practitioners and supervisors alike to construct sustainable and proactive social work: "Instead of despairing about the loss of autonomy, the professionals may go through significant societal and professional transformations as subjects of their own expertise and professional agency."

In a second article for this special issue, Kieran O'Donoghue reports results from 
a survey of registered social workers who are supervisors in Aotearoa New Zealand. The national postal survey of 278 registered social workers supervision gathered data about the background, experiences and views of 138 supervisors. O'Donoghue concludes from his analysis that most supervisors provide supervision that is typical of individual, clinical or professional supervision and is aligned with local professional standards. Echoing the findings from analysing registered social workers' responses in his previous article in this issue, O'Donoghue raises concerns about the predominance of non-Māori supervisors and the cultural relevancy, safety and responsiveness of supervisors for Māori supervisees. O'Donoghue offers a challenge to the SWRB to engage with the matters raised about the diversity and training of the supervisory workforce for social work.

In a Commentary article by Penny Sturt and Bridget Rothwell, 'Implementing the integrated model of supervision: A view from the training room', they explain what the integrated model is and how, as trainers, they use it, and some of the challenges to effective supervision practice that come up in discussions when training supervisors in the UK. Drawing on supervision literature, they present a reinforced $4 \mathrm{Rs}$ model, integrating reflection, restoration, resilience and recording, grounded in the organisational context which influences so much supervision practice.

Finally, this special issue includes two Viewpoint pieces. The first, 'Burnout in social work: The supervisor's role' by Vicki Hirst is based on the author's experience of supervising social workers who have burned out. Hirst's refection addressed the questions: What can I learn from their experience? How does current literature inform supervisory practice in this area? How can I and other supervisors best respond? Hirst's reading of recent literature and professional reflections validated much current supervision practice but introduced some new ideas. She concludes that informed and skilled social work supervisors are well placed to support social workers in preventing burnout, managing it if it does occur, and supporting a return to work, and to the profession as appropriate.

Last up, Craig Holz examines the issues of cost and external supervision in 'A manager's challenge: Is external supervision more valuable than increased training money for staff?' Holz starts with the debate about the relative strengths of external and internal supervision. External supervision is often recommended for professional development reasons, for example, but there is a significant financial cost involved. Internal supervision provides greater oversight of staff and simplifies communication, but issues of power are often significant. Holz presents a hypothetical case study of an agency considering changing its supervision systems and the relative benefits and risks that need to be considered.

We wish to thank all the contributors to this special issue and offer a special thanks to the many anonymous peer reviewers whose work is invisible to readers but which has strengthened the final articles.

\section{References}

Ballantyne, N., Beddoe, L., Hay, K., Maidment, J., Walker S., \& Mayhew, Z. (2019). Enhancing the readiness to practise of newly qualified social workers in Aotearoa New Zealand (Enhance R2P)_Report on phase two: The readiness to practise of NQSWs. Wellington, NZ: Ako Aotearoa.

Beddoe, L., Karvinen-Niinikoski, S., Ruch, G., \& Tsui, M. (2016). Towards an international consensus for a research agenda for social work supervision: Report on the first survey of a Delphi study. British Journal of Social Work, 46(6), 1568-1586.

Beddoe, K. (2017). Harmful supervision: A commentary. The Clinical Supervisor, 36(1), 88-101.

Blom B., Evertsson, L., \& Perlinski. M. (2017). (Eds.), Social and caring professions in European welfare states. Bristol, UK: Policy Press

Carpenter, J., Webb, C., \& Bostock, L. (2013). The surprisingly weak evidence base for supervision: Findings from a systematic review of research in child welfare practice. Children and Youth Services, 35(11), 1843-1853.

Ellis, M. V., Creaner, M., Hutman, H., \& Timulak, L. (2015). A comparative study of clinical supervision in the Republic of Ireland and the United States. Journal of Counseling Psychology, 62(4), 621-631. doi:10.1037/cou0000110 
Hardy, R. (2015, March 17). The social worker who changed my life. The Guardian. Retrieved from https://www. theguardian.com/social-care-network/2015/mar/17/thesocial-worker-who-changed-my-life

Hay, K., Maidment, J., Ballantyne, N., Beddoe, L., \& Walker, S. (2019). Feeling lucky: The serendipitous nature of field education. Clinical Social Work Journal, 47(1), 23-31. doi:10.1007/s10615-018-0688-z

Karvinen-Niinikoski, S., Beddoe, L., Ruch, G., \& Tsui, M.s. (2017). Professional supervision and professional autonomy. In B. Blom, L. Evertsson, \& M. Perlinski (Eds.), Social and caring professions in European welfare states (pp. 53-66). Bristol, UK: Policy Press.

Maben, J., Taylor, C., Dawson, J., Leamy, M., McCarthy, I., \& Reynolds, E., ... Foot, C. (2018). A realist informed mixed-methods evaluation of Schwartz Center Rounds in England. Health Service Delivery Research, 6(37). Retrieved from https://www.ncbi.nlm.nih.gov/books/ NBK533087/

Manthorpe, J., Moriarty, J., Hussein, S., Stevens, M., \& Sharpe, E. (2015). Content and purpose of supervision in social work practice in England: Views of newly qualified social workers, managers and directors. British Journal of Social Work, 45(1), 52-68.

Mor Barak, M. E., Travis, D. J., Pyun, H., \& Xie, B. (2009). The impact of supervision on worker outcomes: $A$ meta-analysis. Social Service Review, 83(1), 3-32. doi:10.1086/599028

O’Donoghue, K., Wong Yuh Ju, P., \& Tsui, M. (2018). Constructing an evidence-informed social work supervision model. European Journal of Social Work, 21(3), 348-358.

Sewell, K. (2018). Social work supervision of staff: A primer and scoping review (2013-2017). Clinical Social Work Journal, 46(4), 252-265.

Turner-Daly, B., \& Gordon, J. (2017). Rhetoric vs. reality in social work supervision: The experiences of a group of child care social workers in England. Child and Family Social Work, 22(1), 36-46.

\section{Liz Beddoe, University of Auckland, New Zealand David Wilkins, Cardiff University, Wales}

